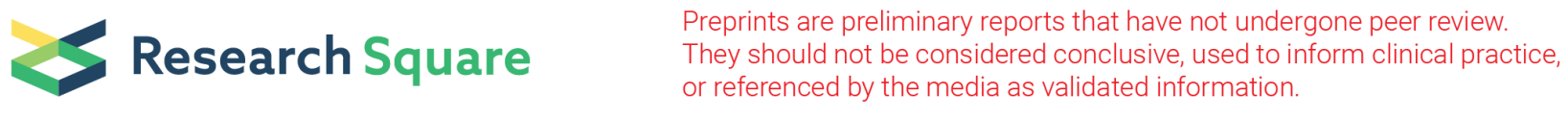

\title{
E Health and Electronic Health Record: The Italian experience in the European Context
}

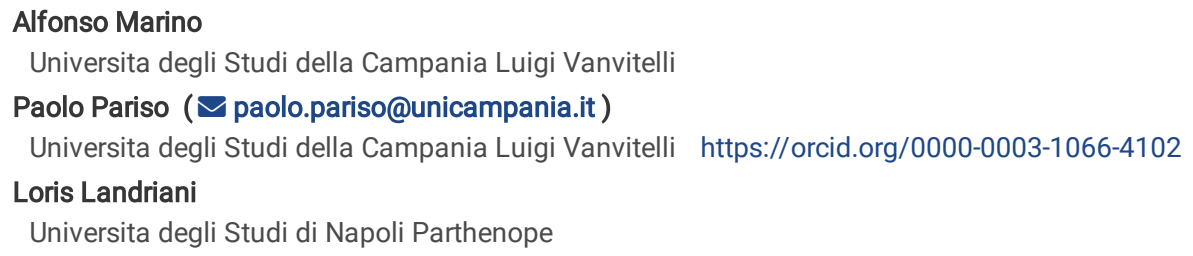

\section{Research article}

Keywords: cross hospital comparative study, Cities, EHR, E Health ICTs diffusion and adoption

Posted Date: June 15th, 2020

DOI: https://doi.org/10.21203/rs.3.rs-31655/v1

License: () (i) This work is licensed under a Creative Commons Attribution 4.0 International License. Read Full License 


\section{Abstract}

Background In the reform context as declared by the Italian Government Law, related to National Health Service, the country are implementing the Information and Communication Technology such as eHealth and Electronic Health Record (EHR). This study aims at evaluating the degree of diffusion and adoption of the Electronic Health Records in southern Italy.

Methods Starting from Italian Regional Inpatient Dataset, that collects data from the hospitals, the study considered several strategic variables in order to assess, within main hospitals of six provincial capitals of southern Italy (Napoli, Bari, Reggio Calabria, Potenza, Palermo, Cagliari), the implementation status of Electronic Health Records. These variables set up Hospital Organizational Indicator and by using SPSS a univariate regression analysis has been developed to obtain descriptive statistics.

Results The results provide a preliminary forecast at the Electronic Health Records' use and suggests that, in their actual implementation, Electronic Health Records have not begun to reach targets and have a smaller impact than expected on hospital organization.

Conclusions The study shows how the EHR is in close correlation with E Health policies and how it can affect such policies as well. The nature of the Italian E Health and applied to the Electronic Health Record showed dated and unsolved bottlenecks within southern Italy, highlighting on the one hand a digital divide between the provision of digital services and the patients and, the on the other hand, a weakness linked to the structure of the organizations based only on rules and procedures and not outcomes and results.

\section{Background}

Electronic Health (E Health) provides both opportunities and challenges for the redesigning of economic and service structures in terms of both production and information worldwide. Therefore, it is no surprising that many European countries are implementing E Health processes. These processes are strictly linked to ICTs [Marino, Pariso, 2019, 2020], and one of the main goals is to ensure the creation of the continuous value in health (Squitieri, et al, 2017; Zhao, et al, 2019). Following this research stream, it is strategic to ensure and activate $E$ Health tools, because it could allow to maintain and add to creation of value in health as in the case of public services (i.e health, education, national and local services). The research, in this study, is focused on E Health tools with particular reference to ICTs diffusion and how these two factors affect Italian Health to create value in the health public sector. These actions are strictly linked to how Italian government operates at micro and macro level using ICT (Bloom, et al, 2019). Since the complexity of service delivery increases over the years as the expectation for transparency of the citizen part, especially in a sector with high technological innovation level (Ash, 1997; Gardner, et al. 2007; Hwang \& Christensen, 2008; Lehoux, et al. 2019;), recent studies highlighted the original character of the E Health and how a government should realize value in health (Eysenbach, \& Jadad, 2001; Oh, H., Rizo, et al. 2005; van Gemert-Pijnen, et al. 2011; Benjamin, et al. 2019). It is interesting to note that, these studies are in line with other conceptual research in which it emerged that the creation of PVs requires to work in alignment, coordination, and co-creation. Creating PVs means changing the programs of public departments. These changes, have been implemented in many Countries and have produced interesting value in health (Norman, \& Skinner, 2006;K elly, et al. 2019; Casado-Vara, \& Corchado, 2019). Such changes, are related to communication, coordination and integration of departments with reference to the new services delivered. These actions and decisions highlight the necessity to negotiate procedures and to reorganize budget and department employees. A recent study argues that these processes are functional to generating positive value in health (Iqbal, et al. 2019; Porter, \& Kramer, 2019; Urena, et al. 2019; Finkelstein, et al. 2019). The governments are operating in a continuously changing context. According to the literature (O'Flynn, 2007; Williams \& Shearer 2011; Chohan, 2019;) conceptualizations of public value the government can improve the collective and individual service delivery (Besley \& Ghatak, 2007; Romzek, et al., 2014). In this sense, the output of a government is aimed at improving public value as a collective goal. Public value means that, public interest and common good should be the main concern of the public sector. It is interesting to note that this approach considers the citizens as effective stakeholders in the process of public value in health creation (Bryson, et al., 2014; Mintrom \& Luetjens, 2017; Cluley \& Radnor 2020). The citizens can determinate a higher level of democracy and legitimate the government, within of two processes of democracy: bottom up and top down. Furthermore, the ICTs are strategic drivers for the enhancement of public value in health. They may be fundamental tools in the processes' optimization to increase the stakeholders' engagement by including also the employees in a network governance logic. In fact, the governments might have to manage and to deliver information, services and gain legitimization in an interactional logic with stakeholders. In this context, ICTs can propose new ideas and models of service delivery. There are interesting contributions that consider ICTs as enabling factors to create public value in health. (Martins, et al., 2019; Ferlie,et al., 2019; Cronemberger \& Gil-Garcia, 2019; Twizeyimana, \& Andersson, 2019). For example, E Health can contribute by improving efficiency and introducing innovation in the delivery of services, by enriching hospital - patient relationships with employees, and by strengthening trust in and support for and legitimacy of health organizations (Miller, et al.,1997; Palanisamy \& Thirunavukarasu, 2019). Following this research stream, E Health is an enabling factor to empower hospital, patient, health service and support inclusive practices especially for the differently process at the national and local level (Krebs, \& Duncan, 2015; Cooper, et al., 2019;). Furthermore, recent studies highlight the potential of ICTs in creating value in health, by enhancing ICTs-relations for the assessment of and intra-hospital services, which produce added value in health. It is interesting to note the different approaches of value in health, Porter (2010, pag 2) argues that: "Value is measured by outputs, not inputs. Hence value in health care depends on the actual patient health outcomes, not the volume of services delivered. More care is not always better care, and shifting focus from volume to value is a central challenge. Nor is value measured by the process of care utilized; process measurement and improvements are important tactics but no substitutes for measuring outcomes and costs". Following this definition, Mosadeghrad (2013, pag 1), proposes a different definition: based on "consistently delighting the patient by providing efficacious, effective and efficient healthcare services according to the latest clinical guidelines and standards, which meet the patient's needs and satisfies providers". The evolution of these studies, related to value E Health are in Campanella et al. (2016), with special reference to Electronic Health Record (EHR) and one of the results shows that EHR systems can improve the value in health. In fact, with reference to the value in health and EHR, Maya et al. (2020) in the conclusion of their paper, argued that "linking individuals' health records with their data-derived family history has untapped potential for supporting diagnostic and clinical decision-making". The studies based on EHR, point out that each public hospital should promote more interactive and active contributions to decision making through timely sharing of information and communication. The result of this process is that ICT would contribute to the creation of value in health by improving hospitals 
action in terms of value and transparency of public services. All these positive elements present a weakness linked to decision making process between professional instance (medical, nursing, technological) and choices of the public health service (Adler-et al., 2015; Desautels, et al., 2016; Tavares, \& Oliveira,

2016). On the one hand, the issue of the assessment of the value in health provision delivers has become strategic over the last few years. On the other hand, governments need guarantee transparency and encourage stakeholder a collaborative participation. In line with these concepts, some studies focused on specific applications to create value in health sector (Graber, et al., 2019; Kruse, et al., 2016). In recent period, February 2020, E health and EHR have been considered strategic assets also in response to the health emergency of the Covid-19. In this context, in order to create an effective balance between value of health service and lockdown, the European countries are turning to a massive use of the E Health. The level of E Health diffusion also represents the extent to which each country is operating in the development, effectiveness, and efficiency of both human and economic advancement. This development process involves the creation of culture (Lepore et al., 2018), investments in network building by including both in the public and private field several sectors (i.e. education, health, economies) at different levels (i.e service delivery, production process). In this context, it is fundamental for the European countries to be able to implement the processes of diffusing and integrating E Health within their societies to translate the benefits in to economic development (European Policy E Health, 2020). The divergence in E Health accessibility and disparity of digital opportunities within European country, with a different distribution among its hospitals, may create bottlenecks to develop value in health. Although, this phenomenon has had a tendency to contract, it is still a critical issue for many European countries (Tuikka, et al., 2016; Grossman, et al., 2016; Bonomi, 2016). The E Health is in close correlation with EHR implementation and use, in fact the chance to efficiently access to this tool represents on the one hand the countries' ability to provide innovative digital services through adequate infrastructures, and, on the other, to guarantee all patients, full access to the opportunities offered by E Health tools. Italy shows a different degree of E Health and EHR implementation and use, within its territory with great differences between the regions. This issue represents an important bottleneck in order to develop E Health. This study assesses EHR diffusion and adoption across Italian southern cities and elaborates the framework of E Health in order evaluate the different degree of digital health present in Italian southern cities and can help to understand how this issue may develop Italian health services. The present analysis will be of interest to researchers, policy makers and government planners, who can acquire information for the development of national $\mathrm{E}$ Health strategies. The paper is organized as follows: section two outlines a conceptual background on the E Health and EHR. Section 3 shows the methodology and Sect. 4 displays the results and related discussion with reference to the Italian experience. Finally, Sect. 5 shows the conclusions of the paper.

The studies on the EHR, starting from a technological point of view, highlight the strategic role of ICT and the extent of the missed opportunities when they are not exploited. Moreover, the EHR is linked to a gap identified as a social issue in particular between the European countries (Katehakis, et al., 2011; McGinn, et al. 2011; Emmanouilidou, \& Burke, 2013). In line with this point of view, EHRs were first linked to ICT access, then also to E Health access, and only later to the development of the information society (Al Aswad et al., 2013; Coorevits, et al., 2013; Nguyen, et al., 2014). These studies represented a critical literature review of some studies to the means of electronic health records by analyzing the advantages and disadvantages from different perspectives and viewpoints related to EHR. The main perspectives of these studies are related to the adoption of electronic health records in different European countries in order to trace out the current status of adopting this technology. These studies highlighted the importance of adoption of electronic health records and the differences among the European countries. The relevant outcomes are linked to the critical points related to the no adoption of EHR. These critical points are related to the organizational, technological and managerial gaps and they concerned national and local health services and nevertheless, the absence of the one European Health Service. However, these studies followed a critical review method of the adoption of EHR starting by its implementation in the European countries. They highlighted that, at organizational level, the critical points are ,on the one hand, linked to the organizations' need to implement ICT in order to effect the changes, and, on the other hand, linked to the insufficient attention of the current culture and procedures to the change goals. In fact, this issue within hospitals, their services' delivery, and medical culture have been analyzed and studied (Strong, et al., 2014; Kazley \& Ozcan 2007). The ICT impact is at multilevel in the organizational change process, and its success, within hospitals, depends on the capability to the management, access, use, and reuse of the informations (Buntin, et al., 2011; Miriovsky, et al., 2012;). The organizational and technological level, should be supported by managerial ones. At managerial level, the studies cited above, suggest that management provides medical ICT training pay attention to it, as strategic outcome. Infact, if this training will done ineffectively can increase managerial risks (Terry, et al., 2008). These variables, linked to organizational, technological and managerial tools, are important to support the hospital information systems. These three approaches, determines an important step forward in assessment of the EHR because, it is associated with the efficient usage as well as information access. These studies were, always, limited and not strongly linked to both pathology and cities context in which there are strategic hospitals that deliver health services. Only in recent years, the literature developed studies in this research line and in Europe less than at worldwide level (Aldosari, 2017; Fukami, \& Masuda, 2019; Joukes, et al., 2019; Martel, et al., 2018; Saleem, \& Herout, J 2018;). In line with this assumption, it is important for the future of Italian health service, to develop studies in relation with the adoption of EHR because recent reforms assign a central role to the strategic hospitals of the city to implement public health policies. The reform, proposed by central government, must be implemented at local level. In this framework, the Public Administration is the main actor in the implementation of EHR activity (Bonacina, et al., 2011; Fernández-Cardeñosa, et al. 2012; Bonomi, et al., 2015;). In this context, the reform is more complex than the E Health as a technological, organizational and managerial issue, by evolving in relation to the concept of the information society. The EHR is studied as an Italian global issue from North to South with tactical decisions to make in all cities where there are strategic hospitals. The pillars related to EHR adoption are three: care, research and governance. Firstly, the care is related to prevention, diagnosis, treatment and rehabilitation. The aim of this pillar is to sustain the Local-Health Service that take care of the patient by means of the Institutions of the National Health Service. Secondly, the research, related to the medical, biomedical and epidemiological sectors. The aim of this pillar is to deliver economic resources within their respective responsibilities assigned by law by means of National Health. Thirdly, the governance linked to the quality of care and evaluation of health care in order to assess organizational, technological and managerial issues. The aims are to coordinate, integrate and control the Local Health Service within their respective responsibilities assigned by law. The debate, linked to HER, within cities with strategic hospitals, highlights the different roles of innovation: organizational, financial, operative (process and service delivery), management, managerial and technological. These are useful for the decision making process of each city's government to establish the course of action to be undertaken in order to improve the public value of Local Health Service. Currently the Covid-19 emergency forces many countries to strengthen the ICT adoption and invest in this way in E Health. For instance, a large part of Italy, particularly the southern Italian experience (Marino, Pariso 2019) but also in other European Countries (Kyriakidou, Michalakelis, \& Sphicopoulos, 2011, 
Ruiz-Rodríguez, Lucendo-Monedero, \& González-Relaño, 2018, Billari, Giuntella, \& Stella, L. 2019) are characterized by very few opportunities for an innovative action related to ICT adoption in E Health. It is interesting to note that Italian government underlines the importance of better performance related to National Health Service through the capacity to utilize the opportunities created by E Health in terms of dissemination of information and knowledge in order to improve individual and collective choices. At Italian local level, regions and cities, in the past and recently, pointed out that the different level of the cities' $\mathrm{E}$ Health widely mirror access and diffusion disparities in ICTs. In many Italian cities, large portions of the population are out of the information society network and run the risk of becoming outcasts. Governments should aim at removing disparities, linked to existing access inequalities. Governments should focus on reform of the public national health service in which the $E$ Health and EHR are strategic bottlenecks which hinder the access to the communication between patients and health. In this logic, if governments wants to implement EHR they need to shed the role of service provider supervision, create favorable conditions, and take actions to ensure equal opportunities for all. This is the design of inclusion. A new frame of mind focused on inclusion is required, and particularly in the Italian southern cities. In Italy, there are still many actions to implement aimed at bridging the E Health and HER (Osservatorio Salute 2018). Will it be possible? In the next section, methodology deals with the approach to adopted to answer the question. Moreover, Sect. 3 and 4 display the results and related discussion and, finally, Sect. 5 shows the conclusions of the paper.

\section{Methods}

\subsection{Data Source}

Starting from data 2019 of Regional Inpatient Database, (RID), the following variables are considered: Healthcare Cost (HC) as Bed Utilization Rate, (HCBUR), Reservation Unique Center and Quality (RUCQ), in order to assess in the following cities' hospital: Napoli (NA) Campania,(RID 2019), Bari (BA) Puglia, (RID 2019), Reggio Calabria (REC) Calabria, (RID, 2019), Potenza (PZ) Basilicata, (RID, 2019), Palermo (PA) Sicilia, (RID,2019), Cagliari (CA) Sardegna, (RID, 2019) the implementation status of EHRs. These cities are all provincial capitals and metropolitan cities. The RID collects data from the hospitals. The hospitals are public, because RID does not collect data from private health. In the selected cities, there are the largest number of hospitals in the region and they are strategic in relation with the guidelines of reform law. These hospitals collect large numbers of patients as residents and people of the region. The considered hospitals have all adopted the EHR during year 2018. RID is a regional database that contains information on patient characteristics, diagnoses, and procedures received. The RID database contains information on Electronic Health Record (HER) utilization in different hospitals along with other important hospital characteristics. Both surgical and medical patients from several diagnostic categories were included in the study. These categories were chosen based on RUCQ dataset and classified as acute diagnosis - ICD9 CM (2020). The greatest number of acute diagnoses are concentrated in a range between 5 and 20 days with relative occupancy of the Bed Utilization Rate. In the considered time, there are remission or the patient's death. These variables set up Hospital Organizational Indicator ( $\mathrm{HOI}$ ). Each $\mathrm{HOI}$ includes a unique denominator, numerator, and set of risk adjustors.

\subsection{Statistical Analysis}

The HOI, are based on Regional codes and Medicare severity diagnosis-related groups (DRGs), with criteria determined by the RUCQ Using Statistical Package for Social Science software (version 26), has been possible to identify adverse events in our dataset. Univariate regression analysis has been developed to obtain descriptive statistics. A hierarchical regression relating level of EHR utilization and quality of care was developed. The independent variables are:

- no HER; (level of EHR utilization)

- partial HER; (level of EHR utilization)

- full HER; (level of EHR utilization)

- patient demographics;

- pathology;

- medical group;

- surgical group.

The dependent variables are:

- mortality;

- readmissions.

measured by HOls.

Relative-risk difference (RrD) used by RUCQ, have been considered in order to implement an EHR system that may improve quality care. All considered hospital have implemented EHR into 2012. This comparison is important in order to eliminate some types of potential confounding. The use of EHR were split into 3 groups: those that gained full EHRs by 2019 (treatment 1), those that gained only partial EHRs by 2019 (treatment 2), and those that still had no EHRs in 2019. Direct comparison of these groups. In order to obtain a logic sequence about EHR use, the rates 2018 are compared within the same hospital's rates in 2019 and the changes (rates) are used to compare the treatment, i.e. EHR adoption level with no EHR adoption. All statistical analyses were performed using SPSS version 26.0 .

\section{Result}


Tables 1 and 2 display patients' characteristics, Table 3 and Table 4 show the results of the cross-sectional analyses respectively of the surgical and medical patients' conditions and cities and hospital patients' conditions. Table 5 displays the results of the association between surgical and medical patients'

conditions with the EHR implementation status. Finally, table 6 shows the results of the association between cities and hospital patients' conditions with the EHR implementation status.

\begin{tabular}{|c|c|c|c|c|c|}
\hline \multicolumn{4}{|c|}{ Table 1 Surgical patient by EHR status - 2019} & \multirow[b]{2}{*}{ Partial EHR } & \multirow[b]{2}{*}{ Full EHR } \\
\hline & & $\mathbf{N}$ & No EHR & & \\
\hline \multirow[t]{7}{*}{ Procedure } & Total & 159859 & 2.70 & 57.84 & 39.73 \\
\hline & NSTEMI & 44.693 & 3.70 & 52.00 & 43.30 \\
\hline & STEMI & 7793 & 3.22 & 56.68 & 40.10 \\
\hline & ANG & 9890 & 2.70 & 58.63 & 38.67 \\
\hline & PUE & 14.748 & 1.49 & 51.53 & 46,98 \\
\hline & CATAM & 74.613 & 2.85 & 55.76 & 41.39 \\
\hline & VEFI & 8122 & 3.00 & 58.44 & 38.56 \\
\hline \multicolumn{6}{|l|}{ Cities } \\
\hline & Napoli & 42.292 & 13.05 & 56.72 & 30.23 \\
\hline & Bari & 31.232 & 7.62 & 54.32 & 38.06 \\
\hline & R Calabria & 33.324 & 5.54 & 57.83 & 36.63 \\
\hline & Potenza & 9232 & 6.32 & 53.64 & 40.04 \\
\hline & Palermo & 25.346 & 5.63 & 54.68 & 39.79 \\
\hline & Cagliari & 18.433 & 4.32 & 58.63 & 37.05 \\
\hline \multicolumn{6}{|l|}{ Age range } \\
\hline & 18 to 39 & 2945 & 2.48 & 56.78 & 40.74 \\
\hline & 40 to 64 & 62.634 & 3.02 & 57.66 & 39.32 \\
\hline & 65 to 74 & 39.824 & 2.33 & 58.75 & 38.92 \\
\hline & $>75$ & 54.456 & 2.78 & 56.76 & 40.46 \\
\hline \multicolumn{6}{|l|}{ Pay ticket } \\
\hline & exemption & 36.686 & 2.82 & 56.42 & 40.76 \\
\hline & partial & 104.384 & 2.32 & 57.34 & 40.34 \\
\hline & full & 18789 & 2.12 & 55.43 & 42.45 \\
\hline
\end{tabular}

begeada

Heart Attack NSTEMI-Code ICD: 41071; Acute myocardial infarction STEMI Code ICD: 41091; Angina ANG Code ICD: 4111; Pulmonary embolism

PUEM Code ICD: 41519; Cardiac tomponade CATAM Code ICD: 4239; Ventricular fibrillation VEFI Code ICD: 42741

\begin{tabular}{|c|c|c|c|c|c|}
\hline & & N & No EHR & Partial EHR & Full EHR \\
\hline \multirow[t]{4}{*}{ Condition } & Total & 332362 & 2,38 & 59,72 & 37,90 \\
\hline & Emergency & 144.693 & 3,70 & 62,00 & 34,30 \\
\hline & Planned & 87794 & 3,11 & 68,08 & 28,81 \\
\hline & Day Hospital & 99875 & 2,30 & 55,63 & 42,07 \\
\hline \multicolumn{6}{|l|}{ Hospital } \\
\hline & Napoli & 82.246 & 14,05 & 54,72 & 31,23 \\
\hline & Bari & 52.214 & 9,62 & 64,32 & 26,06 \\
\hline & R Calabria & 49.124 & 12,54 & 60,83 & 26,63 \\
\hline & Potenza & 45.123 & 4,32 & 63,64 & 32,04 \\
\hline & Palermo & 53.184 & 15,63 & 59,68 & 24,69 \\
\hline & Cagliari & 50.471 & 8,32 & 54,63 & 37,05 \\
\hline \multicolumn{6}{|l|}{ Age range } \\
\hline & 18 to 39 & 4283 & 2,48 & 66,78 & 30,74 \\
\hline & 40 to 64 & 72.755 & 5,02 & 67,66 & 27,32 \\
\hline & 65 to 74 & 69.262 & 4,33 & 56,75 & 38,92 \\
\hline & $>75$ & 186.062 & 4,78 & 59,76 & 35,46 \\
\hline \multicolumn{6}{|l|}{ Pay ticket } \\
\hline & exemption & 134.481 & 6,82 & 59,42 & 33,76 \\
\hline & partial & 179.118 & 3,32 & 58,34 & 38,34 \\
\hline & full & 18763 & 4,12 & 57,43 & 38,45 \\
\hline
\end{tabular}




\begin{tabular}{|c|c|c|c|c|c|}
\hline \multirow{2}{*}{$\begin{array}{l}\text { Tale } 3 \text { cross } 9 \\
\text { Condition } \\
\text { Died } \%\end{array}$} & \multirow{2}{*}{$\begin{array}{l}\text { Group } \\
\text { Total }\end{array}$} & \multirow{2}{*}{$\begin{array}{l}\text { No EHR } \\
1.54\end{array}$} & Partial & Full EHR & $R$ value \\
\hline & & & 1.35 & 1.55 & \\
\hline & NSTEMI & 1.52 & 2.22 & 2.36 & 0.0963 \\
\hline & STEMI & 10.78 & 11.67 & 13.87 & 0.1213 \\
\hline & ANG & 3.04 & 3.03 & 3.07 & 0.7118 \\
\hline & PUE & 2.12 & 1.55 & 1.65 & 0.8655 \\
\hline & CATAM & 1.16 & 0.70 & 0.84 & 0.2812 \\
\hline & VEFI & 1.07 & 0.07 & 0.08 & 0.0234 \\
\hline \multirow[t]{7}{*}{ Emergency \% } & Total & 11.46 & 10.30 & 11.93 & 0.0006 \\
\hline & NSTEMI & 14.62 & 14.65 & 14.67 & 0.8202 \\
\hline & STEMI & 0.00 & 17.63 & 20.32 & 0.0534 \\
\hline & ANG & 10.34 & 11.46 & 12.43 & 0.3520 \\
\hline & PUE & 7.23 & 11.46 & 9.75 & 0.0174 \\
\hline & CATAM & 11.65 & 10.45 & 11.34 & 0.8446 \\
\hline & VEFI & 11.03 & 9.08 & 9.07 & 0.0122 \\
\hline \multirow[t]{7}{*}{ Planned \% } & Total & 3.22 & 3.07 & 3.74 & $<0.0001$ \\
\hline & NSTEMI & 4.35 & 6.27 & 7.35 & $<0.0001$ \\
\hline & STEMI & 3.13 & 12.16 & 13.23 & 0.2054 \\
\hline & ANG & 2.35 & 3.43 & 4.54 & 0.4133 \\
\hline & PUE & 3.65 & 4.13 & 4.33 & 0.5321 \\
\hline & CATAM & 4.62 & 3.49 & 3.86 & 0.1614 \\
\hline & VEFI & 1.62 & 1.10 & 1.27 & 0.0545 \\
\hline \multirow[t]{7}{*}{ Day Hospital \% } & Total & 7.69 & 7.85 & 7.18 & $<0.0001$ \\
\hline & NSTEMI & 14.35 & 10.27 & 10.55 & $<0.0001$ \\
\hline & ST EMI & 13.13 & 12.16 & 12.23 & 0.9054 \\
\hline & ANG & 4.35 & 3.23 & 3.24 & 0.3133 \\
\hline & PUE & 9.65 & 7.13 & 6.33 & 0.0021 \\
\hline & CATAM & 7.62 & 6.49 & 5.86 & 0.0014 \\
\hline & VEF1 & 3.62 & 3.10 & 3.27 & $<0.0001$ \\
\hline
\end{tabular}

\begin{tabular}{|c|c|c|c|c|c|}
\hline Condition & Group & No EHR & Partial EHR & FulleHR & $R$ value \\
\hline \multirow[t]{7}{*}{ Died \% } & Total & 1.64 & 1.55 & 1.75 & 0.0096 \\
\hline & Napoli & 1.82 & 2.33 & 2.42 & 0.0982 \\
\hline & Bari & 10.67 & 16.77 & 10.87 & 0.1236 \\
\hline & Reggio C & 13.04 & 13.73 & 11.57 & 0.9116 \\
\hline & Palermo & 2.82 & 11.58 & 1.63 & 0.8456 \\
\hline & Potenza & 1.13 & 0.60 & 0.74 & 0.2721 \\
\hline & Cagliari & 1.77 & 0.67 & 0.07 & 0.0225 \\
\hline \multirow[t]{7}{*}{ Emergency 96} & Total & 12.54 & 11.34 & 12.73 & 0.0075 \\
\hline & Napoli & 14.22 & 14.15 & 14.17 & 0.8292 \\
\hline & Bari & 10.70 & 13.63 & 21.32 & 0.0634 \\
\hline & Reggio C & 20.34 & 21.46 & 22.43 & 0.5720 \\
\hline & Palermo & 17.23 & 12.47 & 11.77 & 0.0197 \\
\hline & Potenza & 13.65 & 11.45 & 14.44 & 0.8668 \\
\hline & Cagliari & 21.03 & 8.08 & 10.07 & 0.0128 \\
\hline \multirow[t]{7}{*}{ Planned 96} & Total & 3.22 & 3.07 & 3.74 & $<0.0001$ \\
\hline & Napoli & 4.75 & 6.37 & 7.15 & $<0.0001$ \\
\hline & Bari & 13.13 & 12.16 & 13.23 & 0.2134 \\
\hline & Reggio C & 2.55 & 3.13 & 4.54 & 0.4133 \\
\hline & Palermo & 3.65 & 4.23 & 4.13 & 0.6321 \\
\hline & Potenza & 4.82 & 3.79 & 3.46 & 0.1662 \\
\hline & Cagliari & 1.82 & 1.34 & 1.87 & 0.0845 \\
\hline \multirow[t]{7}{*}{ Day Hospital } & Total & 7.29 & 7.45 & 7.38 & $<0.0001$ \\
\hline & Napoli & 15.35 & 13.27 & 10.55 & $<0.0001$ \\
\hline & Bari & 9.13 & 8.16 & 9.23 & 0.8064 \\
\hline & Reggio C & 5.35 & 5.23 & 6.24 & 0.5133 \\
\hline & Palermo & 8.65 & 8.13 & 6.37 & 0.0121 \\
\hline & Potenza & 9.62 & 8.49 & 7.86 & 0.0214 \\
\hline & Cagliari & 5.62 & 6.10 & 4.27 & $<0.0001$ \\
\hline
\end{tabular}

Table 5 Association Between Medical and Surgical Patient and EHR Implementation Status*

\begin{tabular}{|l|l|c|c|c|c|}
\hline Group & Condition & Full EHR vs no EHR OR $(\mathrm{Cl})$ & $R$ value & Partial EHR vs no EHR Or $(\mathrm{Cl})$ & $R$ value \\
\hline Medical & Died & $0.966(0.87 ; 1.05)$ & 0.4729 & $1.003(0.93 ; 1.13)$ & 0.9477 \\
\hline Medical & Emergency & $0.971(0.94 ; 1.04)$ & 0.2748 & $0.985(0.97 ; 1.08)$ & 0.8796 \\
\hline Medical & Planned & $1.067(0.88 ; 1.33)$ & 0.7156 & $1.145(0.95 ; 1.43)$ & 0.2413 \\
\hline Surgical & Died & $1.247(0.97 ; 1.67)$ & 0.1467 & $1.256(0.96 ; 1.68)$ & 0.1798 \\
\hline Surgical & Emergency & $1.039(0.97 ; 1.27)$ & 0.5506 & $1.044(0.96 ; 1.16)$ & 0.5164 \\
\hline Surgical & Planned & $1.233(1.00 ; 1.53)$ & 0.0454 & $1.113(0.93 ; 1.33)$ & 0.2687 \\
\hline
\end{tabular}

*All models were elaborated for age, gender pay ticket, group, hospital size and hospital city

$\mathrm{Cl}=$ confidence interval, EHR=electronic health record, $\mathrm{OR}=$ odds ratio,

$\mathrm{Cl}=95 \% \mathrm{Cl}$

Table 6 Association Between Hospitals (Cities) and condition Patient and EHR Implementation Status* (2018-2019)

\begin{tabular}{|l|l|l|l|c|l|l|}
\hline Cities & Condition & Full EHR vs no EHR OR (C) Rvalue & Partial EHR vs no EHR Or (C) R value \\
\hline Napoli & Day Hospital & $0.921(0.82 ; 1.15)$ & 0.4745 & $1.013(0.83 ; 1.23)$ & 0.94667 \\
\hline Bari & Day Hospital & $0.951(0.92 ; 1.14)$ & 0.2784 & $0.975(0.87 ; 1.18)$ & 0.8776 \\
\hline Reggio C & Planned & $1.027(0.78 ; 1.03)$ & 0.7177 & $1.175(0.85 ; 1.33)$ & 0.2423 \\
\hline Palermo & Planned & $1.222(0.87 ; 1.37)$ & 0.1424 & $1.288(0.86 ; 1.38)$ & 0.1768 \\
\hline Potenza & Day Hospital & $1.019(0.87 ; 1.47)$ & 0.5518 & $1.032(0.86 ; 1.26)$ & 0.5123 \\
\hline Cagliari & Planned & $1.133(1.00 ; 1.23)$ & 0.0436 & $1.121(0.83 ; 1.23)$ & 0.2697 \\
\hline
\end{tabular}

- All models were elaborated for age, gender pay ticket, group, hospital size and hospital city, condition

$\mathrm{Cl}=$ confidence interval, EHR=electronic health record, $\mathrm{OR}=0 \mathrm{dds}$ ratio,

$\mathrm{Cl}=95 \% \mathrm{Cl}$

\section{Discussion}


A total of 159859 surgical and 332362 medical patients, RID dataset, were included. In table 1, the surgical patients display a share of $2.7 \%$ that were treated with no EHR, $57.8 \%$ with partial EHR, and $39.7 \%$ with full EHR. The surgical patients with major number of acute diagnosis are: NSTEMI and CATAM (see legenda table 1). In these two diagnosis NSTEMI display no EHR, 3.70, partial, 52 and full 43.3, CATAM display no EHR 2.85, partial, 55.7 and full 41.3. Furthermore, also in other three acute diagnosis: STEMI, ANG e VEFI, EHR use, display the same trend, with full modality always as last place. The cities with major number of acute considered diagnosis (see legenda Table 1) are: Napoli, Bari, Reggio Calabria. These three cities confirm at the last place full HER and this trend is also shared by other considered cities. Age range displays that the range " 40 to 64 " and " 75 " are those with major numbers of population ( $N$ ). Following the trend, also in this case full EHR is to the last place. "Pay ticket" displays as first modality, "partial payment" with "exemption" at second. Also in this case full EHR is the last modality. In table 2, medical patients show a share of $2.3 \%$ that were treated in a hospital with no EHR, $59.7 \%$ with partial EHR, and 37.9 with full EHR. Naples, with 13 hospitals, is the first city in the Campania Region, and it is the first in the ranking of population ( $\mathrm{N}$ ) affected to acute considered diagnosis. In these hospitals, full EHR is last modality and this position is the same in all considered Hospitals in the cities of ranking. Population after Naples, display the following ranking: Bari, 9 hospitals, $\mathrm{N}=52214$, Palermo, 8 hospitals, $\mathrm{N}=53184$, Cagliari, 7 hospitals, $\mathrm{N}=50471$, Reggio Calabria 5 hospitals, $\mathrm{N}=49124$ and Potenza 2 hospitals, $\mathrm{N}=45123$. The considered cities have the major number of Hospitals in each Region, Bari and Palermo display the major percentage of partial EHR. Assessing the population with "age range" condition, "full HER" is the last modality and "partial payment" of ticket is the first modality linked to population $(\mathrm{N})$ but also in this case "full HER" is for all conditions, the less percentage share. Moreover in Table 3, the cross-sectional analyses displays surgical and medical patients treated with full EHR and mortality rates (1.5) more than patients treated with partial EHR (1.3) but not than patients treated with no EHR (1.5) ( $R$ value 0.0084). "Emergency" condition shows "full HER" rates (11.9) that is greater than both "partial HER" and "no HER" ( $R$ value 0.0006). Also "Planned" condition displays the above described trend with "full HER" rates (3.7) greater than partial and no EHR $(R$ value $<0.0001)$. "Day Hospital" condition, with shorter length of stay, expresses the smallest share in "full HER" (7.1) $(R$ value < 0.0001$)$. The cross-sectional analyses of Cities and hospital patient (table 4), displays that, the first condition is "dead" that is within range of 0.11 with $R$ value 0.0096 , the highest percentage is linked to full HER (1.7). "Emergency" condition displays at the last place "partial HER" and at first place "full HER". This last variable shows a difference with "no HER" condition equal to 0.19 , and the $R$ value is 0.0075 . "Planned" condition displays "no HER" variable with 3.2, "partial EHR" 3.0 and "full HER" 3.7 with $R$ value < 0.0001. "Day hospital" condition instead shows "no HER" 7.2, "partial HER" with 7.4 and "full HER" with 7.3, $R$ value $<0.0001$. These last two conditions display differences between the three modality of EHR (no, partial and full) particularly in planned condition (0.50) while in Day hospital is 0.09 with the same $R$ value. In the table 5, multiple regression analysis, there was no statistically significant difference in two groups: medical and surgical patient. Among medical patient, first condition (died) display in the case of "Full EHR vs no EHR" 0. 96, Odds Ratio (OR) 0.87 and Confidence Interval (Cl) 1.0, $R$ value 0.4729, similar evaluation can be presented in relation to "Partial EHR vs no EHR" with OR 0.9 and CI 1.1, $R$ value 0.9477 . There are statistically significant differences between medical and surgical, "died" rates and R value, both "Full EHR vs no EHR" and "Partial EHR vs no EHR". There are no statistically significant differences in emergency rates among surgical patients treated at hospitals with "Full versus no EHR" or partial versus no EHR. There are no statistically significant differences between rates and $R$ value in emergency condition linked to "Full versus no EHR" or partial versus "no HER". Medical planned displays between "Full versus no EHR" or partial versus "no HER" with a difference of 0.78 with no relevant differences in terms of $\mathrm{CO}$ and $\mathrm{Cl}$. The same trend emerges from the analysis of the group surgical and planned condition in which there are not relevant differences. The differences between the two groups and the same condition are no statistically relevant in relation with "Full versus no EHR" or "partial versus no HER". In the table 6, cities hospital and condition patients, the conditions that emerged are: day hospital and planned, there are correlations with emergency. The "dead" condition, for obvious reasons, has not been assessed. The cities display statistically significant differences, "Day Hospitals" for Napoli, Bari, Potenza and "Planned" for Reggio Calabria, Palermo, Cagliari. There is evidence of reduced risk of surgical patients in hospitals that had full implemented EHRs from 2018 to 2019 . These analyses found statistically significant evidence of an effect in only one case, Cagliari with "Full EHR vs no EHR". In all other cases (group, condition) and modality, "Full EHR vs no EHR" or "Partial EHR vs no EHR" there are no statistically significant correlations.

This study tested the level of EHR implementation in inpatient settings, surgical and medical patient, across 6 cities, large and diverse, all located into southern Italy. The results provided a preliminary foresee at EHR use. Cross-sectional analysis shows significant differences in rates of mortality, emergency and day hospital, between patients at hospitals with "full EHR" or "partial HER" compared to hospitals with "no HER". It is interesting to note that, EHR adoption was not associated to improve quality delivery care. Particularly, in "Emergency" case both surgical and medical, but also in "Planned" and "Day Hospital" conditions there are no statistically significant correlation. The implementation status linked to hospital (cities) highlights only in the city of Cagliari a statistically significant evidence in the case of "Planned" condition. This outcome has been reached in 1 years (2018-2019). Although EHR implementation is thought to improve quality of services, this study, only in southern Italy, suggests that in their actual implementation, EHRs have not begun to reach targets and have a smaller impact than expected on hospital organization. A possible reason for this is that EHRs' effectiveness is not strictly correlated with clinical aspects, and furthermore the use of data for mere reporting purposes has always prevailed in all areas. One example among many: in the case of STEMl; CATAM; VEFI, but also in the other three cases, notifications of access and discharge are transmitted, all post-discharge dressings are reported, but the anatomic-pathological report is almost never transmitted. Furthermore, data suggest that the technological solutions are possible and ready to use, probably, the health care organization and in particular its modality to delivery services should be reorganized by considering the opportunities offered by the technology. It is fundamental develop the awareness that these technologies represent a challenge in terms of change for the current organization of hospital medical work and service delivery. Our study has some limitations. The first concerns the geography area: only southern Italy, even if the 6 cities considered are metropolitan areas and regional capitals. In any case, the regional data of these cities collect the largest number of patients. In addition, this study uses data to identify the level or adoption of the EHR, without assessing if external factors may facilitate the implementation of the EHR.

\section{Conclusion}

The research shows that EHRs adoption in Italian southern cities hospital is not yet a valid response to the challenge posed by the E Health. This issue, in the above mentioned areas, requires a development of information society and the enhancement of the quality of delivery of certain services. This weakness of Italy emerged at both micro and macro level. The Italian E Health and EHR have their roots in the last decades of the 19th century. These E Health processes, 
in Italy, were started later then other Countries and overlap other structural reforms of government. The two main principles that are related to EHRs adoption are:

- The discrepancy between the provision of digital services and the unequal access to and diffusion of information society for patients to ensure communication with local hospitals;

- Hospitals that display structural organizations based on no scientific principles: Italian southern cities hospitals emphasize rules and procedures and not outcomes and results.

Starting from these two observations, the nature of the Italian E Health and EHR highlight dated and unsolved bottlenecks. In line with this statement, the Italian EHR, is complex and debatable particularly in southern Italy. It is interesting to note that, contrary to what the Italian Government reform law stated, it is very difficult to apply the E Health and EHR methods to southern Italy. In this way, an accurate diagnosis of E Health in southern Italy is an imperative in order to understand and implement the proper solutions. The E Health and HER are an open question but it is necessary to rapidly interrupt the vicious circles at micro and macro level. Without this approach it will be impossible to improve the actions and decisions related to the ICTs adoption in Italian southern cities hospital.

\section{Declarations}

\section{Ethics approval and consent to participate}

NOT APPLICABLE

\section{Consent for publication}

NOT APPLICABLE

\section{Availability of data and materials -}

The datasets elaborated and analysed during the current study are available in the repository:

https://www.soresa.it/pa/Pagine/FlussiSanitari.aspx

https://www.dataset.puglia.it/dataset?groups=promozione-della-salute

http://pti.regione.sicilia.it/portal/page/portal/PIR_PORTALE/PIR_LaStrutturaRegionale/PIR_AssessoratoSalute/PIR_AreeTematiche/PIR_Epidemiologia/PIR_Inı https://www.regione.calabria.it/website/organizzazione/dipartimento9/

http://dati.regione.sardegna.it/dataset/sanita

https://www.regione.basilicata.it/giunta/site/giunta/department.jsp?dep=100061\&area=3015722

\section{Competing interests}

NOT APPLICABLE

\section{Funding}

NOT APPLICABLE

\section{Authors' contributions}

NOT APPLICABLE

\section{Acknowledgements}

NOT APPLICABLE

\section{References}

1. Adler-Milstein, J., DesRoches, C. M., Kralovec, P., Foster, G., Worzala, C., Charles, D., ... \& Jha, A. K. (2015). Electronic health record adoption in US hospitals: progress continues, but challenges persist. Health affairs, 34(12), 2174-2180 - 
2. AL-ASWAD, A. M., BROWNSELL, S., PALMER, R., \& NICHOL, J. P. (2013). A review paper of the current status of electronic health records adoption worldwide: the gap between developed and developing countries. Journal of Health Informatics in Developing Countries, 7(2). -

3. Aldosari, B. (2017). Patients' safety in the era of EMR/EHR automation. Informatics in Medicine Unlocked, 9, 230-233.-

4. Ash, J. (1997). Organizational factors that influence information technology diffusion in academic health sciences centers. Journal of the American Medical Informatics Association, 4(2), 102-111. -

5. Benjamin, E. J., Muntner, P., \& Bittencourt, M. S. (2019). Heart disease and stroke statistics-2019 update: a report from the American Heart Association. Circulation, 139(10), e56-e528.-

6. Besley, T., \& Ghatak, M. (2007). Reforming public service delivery. Journal of African Economies, 16(suppl_1), 127-156 -

7. Bloom, D. E., Canning, D., Kotschy, R., Prettner, K., \& Schünemann, J. J. (2019). Health and economic growth: reconciling the micro and macro evidence (No. w26003). National Bureau of Economic Research

8. Bonacina, S., Marceglia, S., \& Pinciroli, F. (2011). Barriers against adoption of electronic health record in Italy. Journal of Healthcare Engineering, 2(4), 509526. -

9. Bonomi, S. (2016). The electronic health record: a comparison of some European countries. In Information and Communication Technologies in Organizations and Society (pp. 33-50). Springer, Cham

10. Bonomi, S., Zardini, A., Rossignoli, C., \& Dameri, P. R. (2015, February). E-health and value co-creation: the case of electronic medical record in an Italian academic integrated hospital. In International Conference on Exploring Services Science (pp. 166-175). Springer, Cham. -

11. Bryson, J. M., Crosby, B. C., \& Bloomberg, L. (2014). Public value governance: Moving beyond traditional public administration and the new public management. Public administration review, 74(4), 445-456)

12. Buntin, M. B., Burke, M. F., Hoaglin, M. C., \& Blumenthal, D. (2011). The benefits of health information technology: a review of the recent literature shows predominantly positive results. Health affairs, 30(3), 464-471

13. Campanella, P., Lovato, E., Marone, C., Fallacara, L., Mancuso, A., Ricciardi, W., \& Specchia, M. L. (2016). The impact of electronic health records on healthcare quality: a systematic review and meta-analysis. The European Journal of Public Health, 26(1), 60-64

14. Casado-Vara, R., \& Corchado, J. (2019). Distributed e-health wide-world accounting ledger via blockchain. Journal of Intelligent \& Fuzzy Systems, 36(3), 2381-2386

15. Chohan, U. W. (2019). Public Value Theory and Budgeting: International Perspectives. Routledge. -

16. Cluley, V., \& Radnor, Z. (2020). Rethinking co-creation: the fluid and relational process of value co-creation in public service organizations. Public Money \& Management, 1-10. -

17. Cooper, Z., Craig, S. V., Gaynor, M., \& Van Reenen, J. (2019). The price ain't right? Hospital prices and health spending on the privately insured. The Quarterly Journal of Economics, 134(1), 51-107.

18. Coorevits, P., Sundgren, M., Klein, G. O., Bahr, A., Claerhout, B., Daniel, C., ... \& De Moor, G. (2013). Electronic health records: new opportunities for clinical research. Journal of internal medicine, 274(6), 547-560

19. Cronemberger, F., \& Gil-Garcia, J. R. (2019). Big Data and analytics as strategies to generate public value in smart cities: Proposing an integrative framework. In Setting foundations for the creation of public value in Smart Cities (pp. 247-267). Springer, Cham. -

20. Data Regional Inpatient Database (RID) Health care 2019

21. https://www.soresa.it/pa/Pagine/FlussiSanitari.aspx

22. https://www.dataset.puglia.it/dataset?groups=promozione-della-salute

23. http://pti.regione.sicilia.it/portal/page/portal/PIR_PORTALE/PIR_LaStrutturaRegionale/PIR_AssessoratoSalute/PIR_AreeTematiche/PIR_Epidemiologia/PI

24. https://www.regione.calabria.it/website/organizzazione/dipartimento9/

25. http://dati.regione.sardegna.it/dataset/sanita

26. https://www.regione.basilicata.it/giunta/site/giunta/department.jsp?dep=100061\&area=3015722

27. Desautels, T., Calvert, J., Hoffman, J., Jay, M., Kerem, Y., Shieh, L., ... \& Wales, D. J. (2016). Prediction of sepsis in the intensive care unit with minimal electronic health record data: a machine learning approach. JMIR medical informatics, 4(3), e28. -

28. Emmanouilidou, M., \& Burke, M. (2013). A thematic review and a policy-analysis agenda of Electronic Health Records in the Greek National Health System. Health policy, 109(1), 31-37.

29. European Policy E Health, 2020) Transformation of Health and Care in the Digital Single Market https://ec.europa.eu/digital-single-market/en/europeanpolicy-ehealth last access June 2020

30. Eysenbach, G., \& Jadad, A. R. (2001). Evidence-based patient choice and consumer health informatics in the Internet age. Journal of medical Internet research, 3(2), e19

31. Ferlie, E., Pegan, A., Pluchinotta, I., \& Shaw, K. (2019). Co-Production and Co-Governance: Strategic Management, Public Value and Co-Creation in the Renewal of Public Agencies across Europe.-

32. Fernández-Cardeñosa, G., de la Torre-Díez, l., López-Coronado, M., \& Rodrigues, J. J. (2012). Analysis of cloud-based solutions on EHRs systems in different scenarios. Journal of medical systems, 36(6), 3777-3782

33. Finkelstein, A., Hendren, N., \& Luttmer, E. F. (2019). The value of medicaid: Interpreting results from the Oregon health insurance experiment. Journal of Political Economy, 127(6), 2836-2874

Page $9 / 11$ 
34. Fukami, Y., \& Masuda, Y. (2019). Success Factors for Realizing Regional Comprehensive Care by EHR with Administrative Data. In Innovation in Medicine and Healthcare Systems, and Multimedia (pp. 35-45). Springer, Singapore. -

35. Gardner, C. A., Acharya, T., \& Yach, D. (2007). Technological and social innovation: a unifying new paradigm for global health. Health Affairs, 26(4), 10521061.

36. Graber, M. L., Siegal, D., Riah, H., Johnston, D., \& Kenyon, K. (2019). Electronic health record-related events in medical malpractice claims. Journal of patient safety, 15(2), 77. -

37. Grossman, Z., Del Torso, S., Van Esso, D., Ehrich, J. H., Altorjai, P., Mazur, A., ... \& Santucci, A. (2016). Use of electronic health records by child primary healthcare providers in Europe. Child: care, health and development, 42(6), 928-933. -

38. Hwang, J., \& Christensen, C. M. (2008). Disruptive innovation in health care delivery: a framework for business-model innovation. Health affairs, 27(5), 1329-1335. -

39. ICD9 CM (2020) https://www.ars.toscana.it/files/pubblicazioni/e-book/Vademecum_ARS.pdf

40. Iqbal, S., Kiah, M. L. M., Zaidan, A. A., Zaidan, B. B., Albahri, O. S., Albahri, A. S., \& Alsalem, M. A. (2019). Real-time-based E-health systems: Design and implementation of a lightweight key management protocol for securing sensitive information of patients. Health and Technology, 9(2), 93-111.

41. Joukes, E., de Keizer, N. F., de Bruijne, M. C., Abu-Hanna, A., \& Cornet, R. (2019). Impact of Electronic versus Paper-Based Recording before EHR Implementation on Health Care Professionals' Perceptions of EHR Use, Data Quality, and Data Reuse. Applied clinical informatics, 10(02), 199-209

42. Katehakis, D. G., Halkiotis, S., \& Kouroubali, A. (2011). Materialization of Regional Health Information Networks in Greece: Electronic Health Record Barriers \& Enablers. Journal of Healthcare Engineering, 2(3), 389-403. -

43. Kazley, A. S., \& Ozcan, Y. A. (2007). Organizational and environmental determinants of hospital EMR adoption: a national study. Journal of medical systems, 31(5), 375-384

44. Kelly, L., Suominen, H., Goeuriot, L., Neves, M., Kanoulas, E., Li, D., ... \& Palotti, J. (2019, September). Overview of the CLEF eHealth evaluation lab 2019. In International Conference of the Cross-Language Evaluation Forum for European Languages (pp. 322-339). Springer, Cham. -

45. Krebs, P., \& Duncan, D. T. (2015). Health app use among US mobile phone owners: a national survey. JMIR mHealth and uHealth, 3(4), e101.

46. Kruse, C. S., Kothman, K., Anerobi, K., \& Abanaka, L. (2016). Adoption factors of the electronic health record: a systematic review. JMIR medical informatics, 4(2), e19

47. Lehoux, P., Roncarolo, F., Silva, H. P., Boivin, A., Denis, J. L., \& Hébert, R. (2019). What health system challenges should responsible innovation in health address? Insights from an international scoping review. International journal of health policy and management, 8(2), 63.-

48. Lepore, L., Metallo, C., Schiavone, F., \& Landriani, L. (2018). Cultural orientations and information systems success in public and private hospitals: preliminary evidences from Italy. BMC health services research, 18(1), 554.

49. Marino, A., Pariso, P. (2019). E-government and Its Impact on National Economic Development: A Case Study Concerning Southern Italy. In Proceedings of the 2019 3rd International Conference on E-commerce, E-Business and E-Government (pp. 1-4). ACM.

50. Marino, A., Pariso, P. (2020). From digital divide to e-government: reengineering process and bureaucracy in public service delivery, DOI: 10.1504/EG.2020.10027735 Electronic Government ,An International Journal

51. Martel, M. L., Imdieke, B. H., Holm, K. M., Poplau, S., Heegaard, W. G., Pryor, J. L., \& Linzer, M. (2018). Developing a medical scribe program at an academic hospital: the Hennepin County Medical Center experience. The Joint Commission Journal on Quality and Patient Safety, 44(5), 238-249.-

52. Martins, T. C. M., Zambalde, A. L., Grützmann, A., de Souza Bermejo, P. H., de Almeida, E. L., \& do Nascimento, T. B. P. (2019, August). Value Innovation in the Public Sector: Concept, Determining Factors and Framework. In International Conference on Electronic Government and the Information Systems Perspective (pp. 163-175). Springer, Cham. -

53. Maya Leventer-Roberts, llan Gofer, Yuval Barak Corren, Ben Y Reis, Ran Balicer Constructing data-derived family histories using electronic health records from a single healthcare delivery system; European Journal of Public Health, Volume 30, Issue 2, April 2020, Pages 212-218

54. McGinn, C. A., Grenier, S., Duplantie, J., Shaw, N., Sicotte, C., Mathieu, L., ... \& Gagnon, M. P. (2011). Comparison of user groups' perspectives of barriers and facilitators to implementing electronic health records: a systematic review. BMC medicine, 9(1), 46. -

55. Miller, N. H., Hill, M., Kottke, T., \& Ockene, I. S. (1997). The multilevel compliance challenge: recommendations for a call to action: a statement for healthcare professionals. Circulation, 95(4), 1085-1090. -

56. Mintrom, M., \& Luetjens, J. (2017). Creating public value: Tightening connections between policy design and public management. Policy Studies Journal, 45(1), 170-190.-

57. Miriovsky, B. J., Shulman, L. N., \& Abernethy, A. P. (2012). Importance of health information technology, electronic health records, and continuously aggregating data to comparative effectiveness research and learning health care. Journal of Clinical Oncology, 30(34), 4243-4248. -

58. Mosadeghrad, A. M. (2013). Healthcare service quality: towards a broad definition. International journal of health care quality assurance. Vol. 26, No. 3, Pp. 203-219, 2013

59. Nguyen, L., Bellucci, E., \& Nguyen, L. T. (2014). Electronic health records implementation: an evaluation of information system impact and contingency factors. International journal of medical informatics, 83(11), 779-796. -

60. Norman, C. D., \& Skinner, H. A. (2006). eHealth literacy: essential skills for consumer health in a networked world. Journal of medical Internet research, $8(2)$, e9. -

61. O'Flynn, J. (2007). From new public management to public value: Paradigmatic change and managerial implications. Australian journal of public administration, 66(3), 353-366 
62. Oh, H., Rizo, C., Enkin, M., \& Jadad, A. (2005). What is eHealth (3): a systematic review of published definitions. Journal of medical Internet research, 7(1), e1. -

63. Osservatorio Salute (2018) http://www.salute.gov.it/portale/documentazione/p6_2_2_1.jsp?lingua=italiano\&id=2651

64. last access $20 / 05 / 2020$

65. https://www.osservatoriosullasalute.it/wp-content/uploads/2019/05/ro-2018.pdf last access 20/05/2020

66. Palanisamy, V., \& Thirunavukarasu, R. (2019). Implications of big data analytics in developing healthcare frameworks-A review. Journal of King Saud University-Computer and Information Sciences, 31(4), 415-425)

67. Porter, M. E. (2010). What is value in health care. N Engl J Med, 363(26), 2477-2481

68. Porter, M. E., \& Kramer, M. R. (2019). Creating shared value. In Managing sustainable business (pp. 323-346). Springer, Dordrecht. -

69. Romzek, B., LeRoux, K., Johnston, J., Kempf, R. J., \& Piatak, J. S. (2014). Informal accountability in multisector service delivery collaborations. Journal of Public Administration Research and Theory, 24(4), 813-842

70. Saleem, J. J., \& Herout, J. (2018, September). Transitioning from one Electronic Health Record (EHR) to another: a narrative literature review. In Proceedings of the Human Factors and Ergonomics Society Annual Meeting (Vol. 62, No. 1, pp. 489-493). Sage CA: Los Angeles, CA: SAGE Publications. $-$

71. Squitieri, L., Bozic, K. J., \& Pusic, A. L. (2017). The role of patient-reported outcome measures in value-based payment reform. Value in Health, 20(6), 834836.

72. Strong, D. M., Volkoff, O., Johnson, S. A., Pelletier, L. R., Tulu, B., Bar-On, I., ... \& Garber, L. (2014). A theory of organization-EHR affordance actualization. Journal of the Association for Information Systems, 15(2), 2. -

73. Tavares, J., \& Oliveira, T. (2016). Electronic health record patient portal adoption by health care consumers: an acceptance model and survey. Journal of medical Internet research, 18(3), e49

74. Terry, A. L., Thorpe, C. F., Giles, G., Brown, J. B., Harris, S. B., Reid, G. J., \& Stewart, M. (2008). Implementing electronic health records: Key factors in primary care. Canadian Family Physician, 54(5), 730-736

75. Tuikka, A. M., Rantanen, M. M., Heimo, O. I., Koskinen, J., Sachdeva, N., \& Kimppa, K. K. (2016). Where is patient in EHR project?. ACM SIGCAS Computers and Society, 45(3), 73-78 - .

76. Twizeyimana, J. D., \& Andersson, A. (2019). The public value of E-Government-A literature review. Government information quarterly

77. Urena, R., Kou, G., Dong, Y., Chiclana, F., \& Herrera-Viedma, E. (2019). A review on trust propagation and opinion dynamics in social networks and group decision making frameworks. Information Sciences, 478, 461-475. -

78. van Gemert-Pijnen, J. E., Nijland, N., van Limburg, M., Ossebaard, H. C., Kelders, S. M., Eysenbach, G., \& Seydel, E. R. (2011). A holistic framework to improve the uptake and impact of eHealth technologies. Journal of medical Internet research, 13(4), e111. -

79. Williams, I., \& Shearer, H. (2011). Appraising public value: Past, present and futures. public administration, 89(4), 1367-1384.-

80. Zhao, R., Yan, R., Chen, Z., Mao, K., Wang, P., \& Gao, R. X. (2019). Deep learning and its applications to machine health monitoring. Mechanical Systems and Signal Processing, 115, 213-237 